\title{
Neurodevelopmental Correlates of Fetal Motor Behavior Assessed Using Cine MR Imaging
}

\author{
(D)T.T.A. Hayat, (D) M. Martinez-Biarge, (D)V. Kyriakopoulou, DJ.V. Hajnal, and (DM.A. Rutherford
} O- $D$

\begin{abstract}
BACKGROUND AND PURPOSE: Fetal motor behavior is widely used as a clinical indicator for healthy development; however, our understanding of its potential as a marker for neurologic integrity is underdeveloped. MR imaging allows complete views of the whole fetus, which, combined with brain imaging, may improve the characterization of this relationship. This study aimed to combine an analysis of fetal motor behavior, brain MR imaging, and postnatal outcome, to provide insight into neurodevelopmental correlates of motor behavior.
\end{abstract}

MATERIALS AND METHODS: Cine MR imaging was used to acquire sequences of fetal motor behavior in subjects with normal and abnormal findings on conventional brain MR imaging between 18 weeks' gestation and term. General movement sequences were analyzed using established criteria. Brain MR imaging was reported by an expert fetal neuroradiologist. Subjects were followed for up to 4 years postnatally with standard postnatal assessments.

RESULTS: Nineteen of 21 fetuses with normal brain MR imaging findings showed normal general movements, compared with 14 of 22 of the fetuses with abnormal brain MR imaging findings, which, when classified by severity of the malformation, showed a significant relationship with postnatal outcome $(P=.021)$. There was a significant relationship among neurodevelopmental outcome, general movement quality, and MR imaging of the brain $(P=.020)$.

CONCLUSIONS: The findings from this study demonstrate that a combined structural and functional imaging approach to the fetus will improve the characterization of early neurologic integrity, with the potential to inform postnatal outcome. This also lays the groundwork for further in vivo research as advanced imaging techniques are developed to study fetal neurologic development.

ABBREVIATION: $G M=$ general movements

M otor impairment is common to many neuropathologic conditions at early stages of development. The assessment of motor function constitutes an important component of the neurologic examination in early infancy, with numerous studies demonstrating that deviations in posture, tone, reflexes, and gross

Received January 31, 2018; accepted after revision April 11.

From the Centre for the Developing Brain (T.T.A.H., V.K., J.V.H., M.A.R.), Perinatal Imaging and Health, Imaging Sciences \& Biomedical Engineering Division, King's College London, London, UK; and Department of Paediatrics (M.M.-B.), Hammersmith Hospital, Imperial College London, London, UK.

This study was supported by a Medical Research Council PhD studentship.

Please address correspondence Tayyib T.A. Hayat, MRCP, PhD, Centre for the Developing Brain, Perinatal Imaging and Health, Imaging Sciences \& Biomedical Engineering Division, King's College London, 1st Floor South Wing, St Thomas' Hospital, London SE1 7EH, United Kingdom; e-mail: tayyib.hayat@nhs.net; @DrTayyib

- Indicates open access to non-subscribers at www.ajnr.org

E Indicates article with supplemental on-line table.

DIndicates article with supplemental on-line video.

http://dx.doi.org/10.3174/ajnr.A5694 and fine motor behavior correlate strongly with neuropathology. ${ }^{1,2}$ Observations of spontaneous motor behavior in the fullterm and preterm infant have demonstrated that deviations in their quality occur in the presence of supraspinal CNS lesions. ${ }^{3}$ The pattern of movements most frequently observed is termed "general movements" (GM), which are characterized by a global sequence of movements of variable speed, amplitude, direction, and fluency. ${ }^{4}$ Disruptions in the GM pattern are characterized by changes in the quality of movements, which are qualitatively described as monotonous and cramped movements, among others. ${ }^{5}$ The GM analysis approach has been extended to the fetus using sonographic imaging; pathologic conditions in the fetus have been associated with a variety of deviant GM patterns. ${ }^{6,7}$ There is evidence to suggest that postnatal GM assessment is predictive of neurologic impairment, ranging from cerebral palsy to cognitive impairment. ${ }^{8,9}$

Sonography has been used for capturing fetal motor behavior at a relatively high temporal resolution. However, the FOV is lim- 
ited; this limitation results in only a partial view of the fetus beyond the gestational age of 20 weeks, thus preventing accurate GM assessment later in pregnancy. Relatively more recently, MR imaging has been explored as a method for observing gross motor activity in the fetus; MR imaging-based studies are taking advantage of the improved global view of the fetus, particularly as it approaches full-term. ${ }^{10-12}$ By means of cine MRI, in an earlier study by our group, changes in fetal motor behavior across gestation were characterized in relation to the volume of available intrauterine space. ${ }^{12}$

In this study, we sought to test the hypothesis that the assessment of the quality of fetal motor behavior using cine MRI is associated with the presence of neurologic abnormalities demonstrated on conventional clinical MR imaging of the brain and is predictive of postnatal neurodevelopmental outcome.

\section{MATERIALS AND METHODS}

Ethics approval was obtained before the start of the study, and written consent was obtained in all subjects. MR images were acquired at the Robert Steiner MRI Unit, Hammersmith Hospital, between October 2007 and February 2010. Subjects were either recruited prospectively as healthy volunteers or referred to the unit following a routine ultrasound requiring further characterization. All subjects had standard clinical MR imaging brain sequences obtained, which were reported by an expert fetal neuroradiologist (M.A.R.).

\section{Cine Image Acquisition}

All imaging examinations were performed on a $1.5 \mathrm{~T}$ Achieva scanner (Philips Healthcare, Best, the Netherlands) using a 5 -channel phased array cardiac coil. Sequence parameters were flip angle, $60^{\circ}$; FOV , $50 \mathrm{~cm}^{2}$; TR/TE, 3.2/1.59 ms; voxel size, $2.2 \times$ $2.2 \mathrm{~mm}$; slice thickness, $30-40 \mathrm{~mm}$; partial Fourier, $62.5 \%$; sensitivity encoding factor, 2 ; specific absorption rate, $2 \mathrm{~W} / \mathrm{kg}$; slice acquisition time, 0.303 seconds; temporal resolution, 3.3 frames per second. Patients were scanned in a lateral tilt position to avoid inferior vena cava compression by the uteroplacental unit, without any sedation. Mothers were not given any specific advice about eating and drinking. All examinations were performed in the morning between 9 AM and 1 PM; no other variable was controlled. Total MR imaging examination time was approximately 60 minutes, including all other clinical and research sequences.

\section{Qualitative Analysis of Fetal Motor Behavior}

The assessment of the quality of motor behavior was based on the criteria for analysis of general movements. ${ }^{3,5,13}$ This motor sequence was selected due to the capability of visualizing the whole fetus with cine MRI, the need for a noninteractive assessment tool, and the established predictive validity of GM analysis in both fetal and ex utero subjects. ${ }^{7,14}$ General movements are defined as a spontaneously generated variable sequence of movements in which there is generalized involvement of the limbs, head, and trunk; the sequence can last from a few seconds to several minutes. The assessment of the quality of GM focuses on 3 main components: fluency-movements should have a smooth appearance and be free from rigidity; variability - a difference in the pattern of movements from one GM to the next; and com- plexity-movements should involve most of the body. GM sequences that fulfill all the above criteria are deemed normal (see On-line Videos 1-3 for examples of normal and 4-6 for examples of abnormal fetal GM).

All GM assessment was performed by 2 raters (T.T.A.H. and M.M.-B.) who had undergone formal training in GM assessment in preterm infants and healthy and unhealthy neonates and were blinded to findings on brain MR imaging. A consensus decision was made on cases in which the individual raters made different assessments.

\section{Assessment of Postnatal Neurologic Outcome}

Outcome data were obtained in the form of postnatal neurologic assessment using the Bayley Scales of Infant Development ${ }^{15}$ or the Griffiths Mental Development Scales. ${ }^{16}$ Assessments were performed by pediatricians experienced with these methods. Other outcomes such as postnatal death, termination of pregnancy, or intrauterine death were also recorded. The aim was to follow the subjects at 12 and 24 months postnatally.

\section{Statistical Analysis}

Statistical analysis was performed using GraphPad Prism software, Version 7.0 (GraphPad Software, San Diego, California). Relationships among GM, structural malformations and neurodevelopmental outcome, GM analysis, and brain MR imaging were analyzed using $\chi^{2}$ and Fisher Exact tests. In the group with abnormal brain imaging findings, a further classification and analysis were made on the basis of the severity of malformation, with subjects with isolated ventriculomegaly classified as "mild," and the others, as "severe." Interrater variability was calculated after a training period using all datasets and was tested using the Cohen $\kappa$ statistic. $P$ values $<.05$ were considered significant.

\section{RESULTS}

Fetal general movements were assessed in 43 pregnancies (median gestational age, 25 weeks; range, 20-36 weeks); the interrater variability was 0.764 (Cohen $\kappa$ ). The median number of GM sequences assessed per fetus was 3 (range, 1-7). Four subjects were lost to follow-up, all of whom were in the subgroup that had normal brain imaging findings and normal GM. The On-line Table summarizes the unhealthy cases, including the findings from the clinical brain images, the movement analysis, and the outcome assessment.

\section{Analysis of the Cohort with Normal Brain MR Imaging Findings}

Twenty-one subjects were included in this cohort (median gestational age, 25 weeks; range, 20-34 weeks), of which 18 were healthy volunteers. The median postnatal follow up was 22 months (range, 1-47 months); 4 subjects were lost to follow-up. Fifteen subjects had a normal outcome, of whom 13 had normal GM. Two subjects had abnormal outcomes (neonatal death associated with premature birth at a gestational age of 26 weeks; mild language delay at 25 months), and both showed normal GM. There was no association between GM and outcome $(P=.583$, Fisher exact test). 


\section{Analysis of the Cohort with Abnormal Brain MR Imaging Findings}

Twenty-two subjects were included in this cohort (median gestational age, 25 weeks; range, 21-36 weeks), all of whom were referred following abnormal ultrasound findings. The median postnatal follow-up was 24 months (range, 12-31 months; On-line Table); none were lost to follow-up. Six pregnancies were terminated, of which 3 showed abnormal GM. Seven subjects had abnormal outcomes, of whom 4 showed abnormal GM. Nine subjects had normal outcomes, of whom 3 showed abnormal GM. There was no association between GM and outcome $(P=.607$, Fisher exact test); subjects were further classified into mild and severe groups based on brain malformations, for which a significant relationship was drawn between GM and outcome $(P=.021$, $\chi^{2}$ test).

\section{Association with Postnatal Neurodevelopmental \\ Outcome}

There was a significant relationship between MR imaging and postnatal outcome ( $P=.004$, Fisher exact test) and among the 3 variables for both cohorts combined: GM assessment, postnatal outcome, and MR imaging brain findings ( $P=.020, \chi^{2}$ test $)$; if the classification combined normal and mild malformations into a single group, the relationship remained positive ( $P=$ .022, $\chi^{2}$ test).

\section{DISCUSSION}

The assessment of GM was originally devised to study the motor function of neonates and preterm infants as a marker of neurologic integrity in a range of conditions. ${ }^{3-5,17,18}$ The presence of GM is stable from its emergence in the first trimester to 3-5 months postterm, which has led to the investigation of fetal GM with ultrasound. ${ }^{6}$ Use of MR imaging was a natural progression and allowed a more detailed view of the fetus, particularly in late gestation. ${ }^{12}$

This study has shown that cine MRI can capture fetal general movements across a wide range of gestational ages and can be used to identify findings of normal and abnormal sequences that are consistent with the GM definitions for premature infants and neonates. A positive association was found among postnatal outcome, structural MR imaging, and GM analysis and suggests that fetal motor assessment may reflect pathologic deviations in CNS development. The data did not reach significance for demonstrating a relationship between GM and outcome in each cohort when classified by structural brain imaging.

The use of brain MR imaging to assess neurologic integrity in the fetus has a caveat: Several studies have shown that structural malformations are associated with a variable clinical outcome. ${ }^{19-21}$ The likely explanation is the capacity for plasticity in the early CNS, which allows a range of normal or mildly abnormal outcomes, despite malformations or insults. Evidence for this has emerged from studies that report neurodevelopmental outcomes after several years of follow-up and which demonstrate a high proportion of neurologically normal outcomes despite structural malformations. ${ }^{22-25}$ Thus, a longer period of follow-up in the present study may allow brain maturation and emergence of the likely long-term neurodevelopmental status for these subjects against which in utero GM assessment could be assessed. On the contrary, other studies with long-term follow-up have shown the emergence of autism and related disorders in individuals with a distribution of incidental CNS lesions similar to those in controls. ${ }^{26}$

There are certain limitations when using cine MRI: In particular, the frame rate generated with the sequence is approximately 3 frames per second, compared with a video, which can be up to 30 frames per second, similar to ultrasound. In a previous study, ${ }^{12}$ we showed that important information pertaining to fetal movement and its complexity was not lost. Also due to the practicalities of MR imaging as an imaging technique, there are limitations on the maximum duration of cine sequence acquisition, which include patient tolerability, limitations due to the specific absorption rate, and the need to acquire other clinical and research data. Given the limitations of ultrasound in the latter half of gestation, further exploration of the role of motor behavioral analysis as 1 element of a complete MR imaging-based fetal neurologic assessment would be justified.

Spontaneous fetal movements are generally considered a barrier to effective MR imaging acquisition due to motion corruption of static brain images. However, as with all ex utero age groups, useful clinical information regarding the integrity of the neuraxis is contained in motor output. This study is limited by its relatively small size and heterogeneous group of neurologic malformations; therefore, the study may not be sufficiently powered to elucidate a positive association. The subgroup with abnormal findings is also very variable in the severity of malformations, and the high representation of ventriculomegaly cases in particular is associated with milder outcomes, some of which require a longer duration of follow-up. ${ }^{20}$ The potential for a mild, if not normal, outcome in the ventriculomegaly subjects may be reflected in the positive relationship between GM and outcome when the group with abnormal findings was further subdivided on the basis of the severity of malformations. This finding is important and suggests that GM analysis has the potential to serve as a biomarker of CNS integrity and add to the assessment provided by brain structure.

There is still a need to improve the understanding of fetal movement and to further explore classifying motor output into normal and pathologic. Further studies may better demonstrate their association with the underlying neurologic integrity, allowing motor patterns to represent a relevant biomarker when combined with emerging functional and structural imaging techniques such as fMRI and tractography. ${ }^{27,28}$ Last, a detailed characterization of motor patterns, with a model of the role of intrauterine constraints, ${ }^{11,29}$ will help develop a comprehensive understanding of the maturation of sensorimotor networks, which, from studies in preterm infants, have been shown to undergo important developmental trajectories early in life and which are likely affected by the physical environmental. ${ }^{30}$

\section{CONCLUSIONS}

This study has provided exploratory data on the use of general movements as a framework for analyzing fetal motor behavior using cine MRI in both neurologically healthy and unhealthy fetuses. Future studies could expand the cohort to include larger homogeneous groups of pathologic conditions and to continue long-term monitoring of subjects to establish the predictive value of fetal GM analysis as a marker of neurologic integrity. This ex- 
pansion may provide a foundation for a framework for the in utero clinical assessment of motor behavior as an adjunct to current approaches and provide a functional marker that could be related to data gathered using advanced imaging techniques that are currently undergoing development.

Disclosures: Joseph V. Hajnal—RELATED: Grant: Medical Research Council, Comments: research grant to support technical and clinical studies focused on MRI of fetuses*; Other: Philips Healthcare, Comments: research support governed by a collaborative research agreement to facilitate advanced use of MRI equipment*; UNRELATED: Grants/Grants Pending: European Research Council, Comments: grant support including for technical development of methods for imaging fetuses. * Mary A. Rutherford—RELATED: Grant: Medical Research Council, Comments: research grant to support technical and clinical studies focused on MRI of fetuses; UNRELATED: Grants/Grants Pending: European Research Council, Comments: grant support including for technical development of methods for imaging fetuses. *Money paid to the institution.

\section{REFERENCES}

1. Saint-Anne Dargassies S. Value of assessing clinical neuropathology at birth. Proc R Soc Med 1971;64:468-71 Medline

2. Dubowitz L, Ricciw D, Mercuri E. The Dubowitz neurological examination of the full-term newborn. Ment Retard Dev Disabil Res Rev 2005;11:52-60 CrossRef Medline

3. Prechtl HF, Einspieler C, Cioni G, et al. An early marker for neurological deficits after perinatal brain lesions. Lancet 1997;349:1361-63 CrossRef Medline

4. Guzzetta A, Mercuri E, Rapisardi G, et al. General movements detect early signs of hemiplegia in term infants with neonatal cerebral infarction. Neuropediatrics 2003;34:61-66 CrossRef Medline

5. Ferrari F, Cioni G, Prechtl HF. Qualitative changes of general movements in preterm infants with brain lesions. Early Hum Dev 1990; 23:193-231 CrossRef Medline

6. de Vries JL, Fong BF. Changes in fetal motility as a result of congenital disorders: an overview. Ultrasound Obstet Gynecol 2007;29:590-99 CrossRef Medline

7. Rosier-van Dunné FM, van Wezel-Meijler G, Bakker MP, et al. Fetal general movements and brain sonography in a population at risk for preterm birth. Early Hum Dev 2010;86:107-11 CrossRef Medline

8. Ferrari F, Cioni G, Einspieler C, et al. Cramped synchronized general movements in preterm infants as an early marker for cerebral palsy. Arch Pediatr Adolesc Med 2002;156:460-67 CrossRef Medline

9. Einspieler C, Bos AF, Libertus ME, et al. The general movement assessment helps us to identify preterm infants at risk for cognitive dysfunction. Front Psychol 2016;7:406 CrossRef Medline

10. Shen SH, Guo WY, Hung JH. Two-dimensional fast imaging employing steady-state acquisition (FIESTA) cine acquisition of fetal non-central nervous system abnormalities. J Magn Reson Imaging 2007;26:672-77 CrossRef Medline

11. Verbruggen SW, Loo JH, Hayat TTA, et al. Modeling the biomechanics of fetal movements. Biomech Model Mechanobiol 2016;15:9951004 CrossRef Medline

12. Hayat TTA, Nihat A, Martinez-Biarge M, et al. Optimization and initial experience of a multisection balanced steady-state free precession cine sequence for the assessment of fetal behavior in utero. AJNR Am J Neuroradiol 2011;32:331-38 CrossRef Medline
13. Einspieler C, Prechtl HF. Prechtl's assessment of general movements: a diagnostic tool for the functional assessment of the young nervous system. Ment Retard Dev Disabil Res Rev 2005;11:61-67 CrossRef Medline

14. Burger M, Louw QA. The predictive validity of general movements: a systematic review. Eur J Paediatr Neurol 2009;13:408-20 CrossRef Medline

15. Bayley N. Bayley Scales of Infant and Toddler Development. San Antonio: Psychological Corporation; 2006

16. Griffiths R. The Griffiths Mental Development Scales from Birth to 2 Years, Manual, 1996 Revision. Henley, UK: Association for Research in Infant and Child Development Test Agency; 1996

17. van Iersel PA, Bakker SC, Jonker AJ, et al. Quality of general movements in term infants with asphyxia. Early Hum Dev 2009;85:7-12 CrossRef Medline

18. Hadders-Algra M, Mavinkurve-Groothuis AM, Groen SE, et al. Quality of general movements and the development of minor neurological dysfunction at toddler and school age. Clin Rehabil 2004;18: 287-99 CrossRef Medline

19. Poretti A, Limperopoulos C, Roulet-Perez E, et al. Outcome of severe unilateral cerebellar hypoplasia. Dev Med Child Neurol 2010;52: 718-24 CrossRef Medline

20. Gaglioti P, Danelon D, Bontempo S, et al. Fetal cerebral ventriculomegaly: outcome in $\mathbf{1 7 6}$ cases. Ultrasound Obstet Gynecol 2005;25:372-77 CrossRef Medline

21. Chervenak FA, Duncan C, Ment LR, et al. Outcome of fetal ventriculomegaly. Lancet 1984;2:179-81

22. Tarui T, Limperopoulos C, Sullivan NR, et al. Long-term developmental outcome of children with a fetal diagnosis of isolated inferior vermian hypoplasia. Arch Dis Child Fetal Neonatal Ed 2014;99: F54-58 CrossRef Medline

23. Bar-Yosef O, Barzilay E, Dorembus S, et al. Neurodevelopmental outcome of isolated ventriculomegaly: a prospective cohort study. Prenat Diagn 2017;37:764-68 CrossRef Medline

24. Letouzey M, Chadie A, Brasseur-Daudruy M, et al. Severe apparently isolated fetal ventriculomegaly and neurodevelopmental outcome. Prenat Diagn 2017;37:820-26 CrossRef Medline

25. Cooper S, Katorza E, Berkenstadt M, et al. Prenatal abnormal width of the cavum septum pellucidum: MRI features and neurodevelopmental outcome. J Matern Fetal Neonatal Med 2017 Aug 16. [Epub ahead of print] CrossRef Medline

26. Monterrey JC, Philips J, Cleveland S, et al. Incidental brain MRI findings in an autism twin study. Autism Res 2017;10:113-20 CrossRef Medline

27. Seshamani S, Blazejewska AI, Mckown S, et al. Detecting default mode networks in utero by integrated $4 \mathrm{D}$ fMRI reconstruction and analysis. Hum Brain Mapp 2016;37:4158-78 CrossRef Medline

28. Marami B, Mohseni Salehi SS, Afacan O, et al. Temporal slice registration and robust diffusion-tensor reconstruction for improved fetal brain structural connectivity analysis. Neuroimage 2017;156: 475-88 CrossRef Medline

29. Verbruggen SW, Oyen ML, Phillips ATM, et al. Function and failure of the fetal membrane: modelling the mechanics of the chorion and amnion. PLoS One 2017;12:e0171588 CrossRef Medline

30. Allievi AG, Arichi T, Tusor N, et al. Maturation of sensori-motor functional responses in the preterm brain. Cereb Cortex 2016;26: 402-13 CrossRef Medline 